\title{
Diving beyond Aerobic Limits: Effect of Temperature on Anaerobic Support of Simulated Predator Avoidance Dives in an Air-Breathing Ectotherm
}

\author{
Essie M. Rodgers ${ }^{\star}$ \\ Craig E. Franklin ${ }^{\dagger}$ \\ School of Biological Sciences, University of Queensland, \\ Brisbane, Queensland 4072, Australia
}

Accepted 1/27/2019; Electronically Published 3/13/2019

\begin{abstract}
Diving optimality models predict air breathers to routinely dive within aerobic limits, but predator avoidance dives may be an exception. Lengthening submergence times during a predation threat may enhance survival probability, and we therefore hypothesized that predator avoidance dives in juvenile estuarine crocodiles (Crocodylus porosus) would be partially anaerobically fueled. We also predicted that reliance on anaerobic metabolism would increase at elevated temperatures to offset the faster depletion of body oxygen stores. Crocodiles were maintained at $28^{\circ}$ and $34^{\circ} \mathrm{C}$ for $60 \mathrm{~d}$ and subsequently underwent simulated predator avoidance dive trials at two test temperatures $\left(28^{\circ}\right.$ and $\left.34^{\circ} \mathrm{C}\right)$. Blood was sampled immediately on surfacing to measure plasma lactate concentrations relative to nondiving (control) values. Aerobic dive limits (cADL; min) were also calculated using known body mass and oxygen storage relationships and rates of diving oxygen consumption and compared with observed dive durations. Postdive plasma lactate levels were elevated beyond resting levels at both test temperatures, indicating that aerobic thresholds were surpassed during simulated predator avoidance dives. Similarly, $\geq 90 \%$ of dive durations exceeded cADLs at both test temperatures. Postdive plasma lactate concentrations were independent of water temperature and thermal acclimation treatment. Together, these findings suggest that reliance on anaerobiosis during simulated predator avoidance dives is important regardless of temperature.
\end{abstract}

\footnotetext{
*Present address: Systemic Physiological and Ecotoxicological Research, Department of Biology, University of Antwerp, Groenenborgerlaan 171, BE-2020 Antwerp, Belgium.

${ }^{\dagger}$ Corresponding author; email: c.franklin@uq.edu.au.
}

Physiological and Biochemical Zoology 92(3): 293-302. 2019. (C) 2019 by The University of Chicago. All rights reserved. 1522-2152/2019/9203-8086\$15.00. DOI: $10.1086 / 702828$
Keywords: diving behavior, anaerobic metabolism, anaerobiosis, Crocodylus porosus, aerobic dive limit, diving lactate threshold, estuarine crocodile, predation risk.

\section{Introduction}

Maximizing time available for diving is considered adaptive in many air-breathing aquatic species where predator avoidance and prey pursuits occur underwater (Kramer 1988). However, owing to a negligible capacity for aquatic respiration, dive durations are constrained by total body oxygen (TBO) stores and the rate at which these are consumed by metabolic processes (Butler 2006). The maximum duration an air-breathing animal can remain submerged before blood lactate levels rise beyond resting levels is termed the aerobic dive limit (ADL; Kooyman 1989; Butler 2006). An animal's ADL can be calculated (cADL) by dividing its TBO stores by the rate at which oxygen is consumed (i.e., diving metabolic rate). Submergences can extend beyond aerobic thresholds by employing anaerobic pathways, but there are associated costs, including a buildup of lactate and exhaustion (Butler 2006).

Diving beyond aerobic thresholds by employing anaerobic pathways comes at the cost of extended postdive recovery periods where oxygen debt is repaid and lactic acid is metabolized (Kooyman et al. 1980; Costa et al. 2004). Gains in dive duration from anaerobiosis are disproportionately low compared with obligate recovery periods (Kooyman et al. 1980, 1983). Moreover, anaerobiosis is an inefficient use of energy substrate and generates only one-eighteenth of adenosine triphosphate if glucose is the substrate compared with aerobic metabolism (Boyd 1997). For these reasons, diving optimality models predict air breathers to routinely dive within aerobic limits, thereby minimizing recovery times and maximizing cumulative underwater time (Kramer 1988; Houston and McNamara 1992; Boyd 1997). However, predator avoidance dives may be an exception (Heithaus and Frid 2003). Predation risk typically increases with proximity to the water surface because of increased conspicuousness to both aerial and subsurface predators (Heithaus and Frid 2003). The visibility of aquatic predators in deep water is also reduced (Strong 1996; Heithaus et al. 2002). Lengthening dive times via anaerobiosis during a predation threat may therefore enhance survival probability. Yet the extent to which predator avoidance dives are fueled anaerobically remains untested in air-breathing divers.

Predation pressure is generally greatest during early life-history stages. Juvenile and hatchling crocodylians, for example, can fall 
prey to a range of aerial and aquatic predators, including whistling kites, herons, olive pythons, barramundi, and larger crocodiles (Grigg and Kirshner 2015). Diving is an integral component of crocodylian behavior, and telemetry has revealed frequent dives (50-70 dives $\mathrm{d}^{-1}$; Grigg et al. 1985; Franklin et al. 2009; Campbell et al. 2010). Simulated predator avoidance dives in juvenile estuarine crocodiles, Crocodylus porosus (Schneider 1801), generally last 7-30 min (Rodgers et al. 2015) and are accompanied by physiological alterations, termed the dive response (Wright et al. 1992; Rodgers and Franklin 2017). The dive response encompasses a suite of changes that lower oxygen demands, including a precipitous decline in heart rate $(\sim 65 \%$ lower than surface heart rate; Wright et al. 1992), a redistribution of blood to essential organs (i.e., peripheral vasoconstriction), and a cardiac shunt (Axelsson and Franklin 1997; Franklin and Axelsson 2000). These physiological alterations may serve to prolong predator avoidance dives, but water temperature mediates the extent of these alterations (Rodgers and Franklin 2017).

Water temperature has an overbearing influence on submergence times of crocodylians and other ectothermic divers (Storey et al. 2008; Samajova and Gvozdik 2009; Rodgers et al. 2015). ADLs decline with rising temperatures in ectotherms because of the tight relationship between environmental and body temperature, coupled with the thermal sensitivity of metabolism (Hayward et al. 2016). Shorter dive durations at elevated water temperatures have been observed in numerous ectothermic vertebrates, including sea snakes, estuarine crocodiles, alpine newts, and freshwater turtles (Priest and Franklin 2002; Clark et al. 2008; Storey et al. 2008; Samajova and Gvozdik 2009; Pratt and Franklin 2010; Rodgers et al. 2015; Udyawer et al. 2016). Likewise, submergence times of free-ranging freshwater crocodiles (Crocodylus johnstoni) and marine and freshwater turtles are shorter in summer compared with winter (Carr et al. 1980; Gordos et al. 2003; Hochscheid et al. 2005, 2007; Bradshaw et al. 2007; Campbell et al. 2010).

The thermal sensitivity of crocodylian dive performance has spurred research investigating the potential effects of climate warming on predator avoidance dive capacity in C. porosus (Rodgers et al. 2015; Rodgers and Franklin 2017). Predator avoidance dive durations are predicted to halve under a high magnitude of climate warming, and physiological acclimation responses appear limited (Rodgers et al. 2015; Rodgers and Franklin 2017). However, the deleterious effects of elevated temperatures on dive performance may be offset by increasing reliance on anaerobic metabolism. Examinations of free-ranging diving behavior suggest that freshwater crocodiles increase reliance on anaerobiosis in warmer months. Postdive surface intervals in C. johnstoni were significantly lengthened in summer compared with winter, suggesting that recovery periods were required to repay oxygen debt and metabolize lactic acid (Campbell et al. 2010). Yet no empirical evaluations of how water temperature influences anaerobic support of predator avoidance dives exist.

We used juvenile $C$. porosus as a model species to investigate whether simulated predator avoidance dives are supported by anaerobiosis and whether water temperature modulates their reliance on anaerobiosis, as observed in free-ranging $C$. johnstoni. We hypothesized that predator avoidance dives would be partially fueled by anaerobic metabolism $\left(H_{1}\right)$ and that crocodiles would increase their reliance on anaerobic metabolism at elevated temperatures in an effort to prolong dive durations $\left(H_{2}\right)$. To test these predictions, juvenile $C$. porosus were chronically maintained at two temperatures (designed to emulate climate warming scenarios) before undergoing simulated predator avoidance dives at two test temperatures, where blood was sampled immediately on surfacing. Plasma lactate concentration was used as a proxy for anaerobic reliance and was compared with samples obtained from resting crocodiles, and crocodiles run to exhaustion to estimate maximal anaerobic capacity. Postdive plasma lactate levels were expected to be above resting levels but below maximal levels, as energy may be reserved for replenishing oxygen stores and potential antagonistic interactions with predators. ADLs were also calculated using known body mass and oxygen storage relationships (Wright 1985) and known rates of diving oxygen consumption (Rodgers and Franklin 2017). Together these data were used to assess whether predator avoidance dives are anaerobically supported and whether increased reliance on anaerobic metabolism occurs at elevated temperatures to compensate for shorter ADLs.

\section{Methods}

\section{Animal Maintenance and Thermal Acclimation Treatments}

Animal husbandry and thermal acclimation protocols were identical to those outlined by Rodgers and Franklin (2017). Briefly, estuarine crocodile eggs (Crocodylus porosus) were sourced from David Fleay Wildlife Park (Burleigh Heads, Queensland) and juveniles were obtained from Cairns Crocodile Farm (Gordonvale, Queensland; $N=14$ from four clutches; six reared from eggs; eight obtained as juveniles). Before testing, crocodiles were acclimated to a common water temperature of $31.5^{\circ} \pm 0.5^{\circ} \mathrm{C}$ for 3 mo to counteract differences in thermal histories. Enclosures $(3.35 \mathrm{~m} \times 0.85 \mathrm{~m} \times 0.75 \mathrm{~m})$ contained freshwater filled to a depth of $0.15 \mathrm{~m}$ and had a dry platform situated underneath a ceramic heat lamp ( $250 \mathrm{~W}$; OzWhite, Enfield, South Australia; suspended $26 \mathrm{~cm}$ above the platform) and an ultraviolet B (UV-B) light (25 W; Exo Terra, Montreal). Heat lamps were on for $8 \mathrm{~h} \mathrm{~d}^{-1}(0800$ 1600 hours), with substrate temperatures underneath the heat lamp averaging $40^{\circ} \pm 3^{\circ} \mathrm{C}$ (mean $\pm \mathrm{SD}$ ). The UV-B light was used to emulate a summer photoperiod, with a $14 \mathrm{~L}: 10 \mathrm{D}$ regimen (0500-1900 hours light) for all treatments. A random number generator was used to assign crocodiles to one of two thermal acclimation treatments (water temperature: $28^{\circ} \pm 0.5^{\circ} \mathrm{C}$ or $34^{\circ} \pm 0.5^{\circ} \mathrm{C}$ ), but assignment occurred separately for crocodiles from each source to ensure equal distribution between treatments $\left(N=5-6\right.$ treatment $\left.^{-1}\right)$. Terrestrial space and access to heat lamps and UV-B lights, as described above, were identical in both thermal acclimation treatments. Crocodiles were held in thermal acclimation treatments for $60 \mathrm{~d}$ before simulated predator avoidance dive trials. Animal care and experimental protocols complied with University of Queensland animal ethics requirements (approval SBS/018/14/ARC/AUST ZOO). 
Simulated Predator Avoidance Dives

Dive trials were held in a custom-built foam fiberglass tank $(1.8 \mathrm{~m} \times 2.0 \mathrm{~m} \times 1.9 \mathrm{~m})$ filled with freshwater to a depth of $1.3 \mathrm{~m}$. Water temperature was finely controlled using a spa heater (900 EVO, Elecro Engineering, Stevenage). Thermal profiling using temperature loggers (iButtonLink Technology, Whitewater, WI) confirmed uniformity of temperature throughout the water column. The dive tank contained a floating platform $(0.6 \mathrm{~m} \times$ $0.15 \mathrm{~m} \times 0.05 \mathrm{~m}$ ), where crocodiles could rest and breathe on the water surface while their body remained underwater. Simulated predator avoidance dive performance (i.e., minutes submerged) was assessed at two test temperatures (i.e., $28^{\circ}$ and $34^{\circ} \mathrm{C}$ ). Crocodiles were fasted for $48 \mathrm{~h}$ before dive trials and were tested individually. Animals were placed in the dive tank the night before their trial to ensure that plasma lactate levels returned to resting levels after handling (Franklin et al. 2003). Following the habituation period, either a single simulated predator avoidance dive trial or a series of consecutive simulated predator avoidance dives began. The single-dive trial involved just one dive, whereas the consecutive dive trial involved a bout of four dives with fixed surface intervals of $3.6 \pm 0.6 \mathrm{~s}$ (mean $\pm \mathrm{SD}$ ). Dive trials were designed to simulate the presence of a predator where crocodiles dived underwater as an escape behavior. Predator avoidance dives were simulated by making a loud auditory disturbance, created by the experimenter tapping the side of the dive tank with a blunt wooden pole. The experimenter was in view of the crocodile throughout the dive trial to simulate the prolonged presence of a predator. Dive durations were directly observed and timed.

\section{Blood Sampling and Analyses}

Crocodiles were immediately captured on surfacing at the end of a trial for blood sampling. Blood samples $(0.5-2 \mathrm{~mL})$ were drawn from a branch of the jugular vein (venous blood) using 0.5 -in 23-gauge needles attached to heparinized (lithium salt; Sigma) syringes. Blood was centrifuged (Microfuge 18, Beckman Coulter, Lane Cove) in Eppendorf tubes at 2-5 relative centrifugal force for $3 \mathrm{~min}$, and plasma was subsequently withdrawn and stored in a $-80^{\circ} \mathrm{C}$ freezer until lactate analyses. Plasma lactate concentrations $\left(\mathrm{mmol} \mathrm{L}^{-1}\right)$ were measured using a lactate meter (Lactate Pro 2, Phill Bates sports promotions, Carlton), where $5 \mu \mathrm{L}$ of thawed plasma was placed on test strips. Blood samples were also taken from resting and exercise-exhausted animals for reference points. Resting blood samples were obtained by capturing animals in their holding tank and immediately sampling. Blood samples were also obtained after exercising animals to exhaustion (typically 5-7 $\mathrm{min}$ ). Exercise was induced by stimulating crocodiles to run inside a Nally container $(71.1 \mathrm{~cm} \times 43.8 \mathrm{~cm} \times 28.3 \mathrm{~cm})$ by lightly touching their tails and gently turning animals on their back which elicited a righting response. Animals were considered exhausted when they were unable to right themselves, and blood was immediately sampled. Exercise trials were conducted inside a temperature-controlled room, with air temperatures matching the crocodiles' acclimation temperature (i.e., $28^{\circ}$ or $34^{\circ} \mathrm{C}$ ). Blood sampling times were recorded, and all samples were obtained within $3 \mathrm{~min}$ to avoid lactate generated by handling stress con- taminating the sample (Finger et al. 2015a, 2015b). All crocodiles participated in multiple trials (five to six trials; resting, exercise exhausted, and single dive and consecutive diving at $28^{\circ}$ and $34^{\circ} \mathrm{C}$ ) and were provided a $7-\mathrm{d}$ recovery period in their thermal acclimation holding tanks between trials.

\section{Estimating Total Body Oxygen Stores and Aerobic Dive Limits}

Pulmonary ( 67\% TBO), blood ( 28.9\% TBO), and muscle ( $\sim 4.1 \% \mathrm{TBO}$ ) oxygen stores were estimated on the basis of mean crocodile body mass $\left(M_{\mathrm{b}}=408.1 \pm 164.4 \mathrm{~g}\right.$; mean $\left.\pm \mathrm{SD}\right)$ and summed to determine TBO stores (Wright 1985). Lung volume $(\mathrm{mL})$ of juvenile $C$. porosus scales allometrically with $M_{\mathrm{b}}$, with an exponent of $0.906\left(N=24 ; r^{2}=0.96, P<0.01\right.$; Wright and Kirshner 1987). Blood volume was assumed to be the same as the American alligator (Alligator mississippiensis; $72.7 \mathrm{~mL} \mathrm{~kg}^{-1}$; Huggins 1961), and muscle volume was assumed to be $500 \mathrm{~mL} \mathrm{~kg}^{-1}$ (Wright 1985). Equations derived by Wright (1985) were used to estimate blood and muscle oxygen stores at body temperatures calibrated at $30^{\circ} \mathrm{C}$, such that

$$
\begin{aligned}
\text { pulmonary } \mathrm{O}_{2} & =12.8 \times 10^{-3} \mathrm{M}_{\mathrm{b}}{ }^{0.906}, \\
\text { muscle } \mathrm{O}_{2} & =0.42 \times 10^{-3} M_{\mathrm{b}}, \\
\text { blood } \mathrm{O}_{2} & =4.7 \times 10^{-3} \mathrm{M}_{\mathrm{b}} .
\end{aligned}
$$

Calculated ADLs (cADL; min) were estimated using Butler's (2006) equation:

$$
\mathrm{cADL}=\frac{\mathrm{TBO}}{\mathrm{DMR}}
$$

where $\mathrm{TBO}$ is the sum of pulmonary, muscle, and blood $\mathrm{O}_{2}$ stores $(\mathrm{mL})$ and $\mathrm{DMR}$ is predator avoidance diving metabolic rate $\left(\mathrm{mL} \mathrm{O}_{2} \mathrm{~min}^{-1}\right)$. cADLs were estimated for two water temperatures $\left(28^{\circ}\right.$ and $\left.34^{\circ} \mathrm{C}\right)$ using published values of DMR in juvenile C. porosus conducting predator avoidance dives (Rodgers and Franklin 2017), where

$$
\begin{aligned}
& \operatorname{DMR}\left(28^{\circ} \mathrm{C}\right)=0.62 \mathrm{O}_{2} \mathrm{~mL} \mathrm{~min}^{-1}, \\
& \operatorname{DMR}\left(34^{\circ} \mathrm{C}\right)=2.05 \mathrm{O}_{2} \mathrm{~mL} \mathrm{~min}^{-1} .
\end{aligned}
$$

\section{Statistical Analyses}

Data analyses were performed in R Studio (ver. 3.1.3; R Development Core Team 2012) using the nlme (linear and nonlinear mixed effects models; https://CRAN.R-project.org/package = nlme) and multcomp (simultaneous inference in general parametric models; https://CRAN.R-project.org/package = multcomp) packages. Two linear mixed effects (LME) models were run to determine the effects of test temperature, thermal acclimation treatment, and dive duration on postdive plasma lactate accumulation $\left(\mathrm{mmol} \mathrm{L}^{-1}\right)$ following single and consecutive simulated predator avoidance dives. Test temperature (two-level factor), acclimation treatment (two-level factor), and dive duration were included as fixed effects, and body mass was included as a covariate. Animal source (i.e., Cairn's Crocodile Farm or David Fleay Wildlife Park) and identification number (ID) were included as random effects (ID nested within source). A separate LME model was run to assess 
the effect of blood sampling time (min) on plasma lactate accumulation and compare lactate accumulation between different activity states (i.e., resting, exercise exhausted, single simulated predator avoidance dive, and consecutive simulated predator avoidance diving). A Tukey's post hoc test was run to discern statistical differences between activity states. Two LME models were run to assess the effect of water temperature on single and consecutive dive durations, where test temperature and acclimation treatment were fixed effects, animal ID and source were random effects, and body mass was included as a covariate. Minimal adequate models were determined using maximum likelihood simplification. $P \leq 0.05$ was considered statistically significant.

\section{Results}

Effect of Water Temperature on Submergence Times

Test temperature significantly affected dive durations in both single $\left(P<0.05, F_{1,7}=8.0\right.$; LME $)$ and consecutive $(P<0.001$, $\left.F_{1,9}=27.4 ; \mathrm{LME}\right)$ predator avoidance dives. In single-dive trials, crocodiles spent an average of $16.5 \pm 4.4$ min (mean \pm SE) underwater at $28^{\circ} \mathrm{C}$ compared with $9.8 \pm 0.9 \min ($ mean $\pm \mathrm{SE}$ ) at $34^{\circ} \mathrm{C}$ (fig. $1 \mathrm{~A}$ ). Likewise, crocodiles spent a total of $63.6 \pm$ 11.7 min (mean $\pm \mathrm{SE}$ ) submerged at $28^{\circ} \mathrm{C}$ during consecutive predator avoidance dives compared with $28.1 \pm 1.3 \mathrm{~min}$ (mean $\pm \mathrm{SE}$ ) at $34^{\circ} \mathrm{C}$ (fig. $1 B$ ). Dive durations were independent of thermal acclimation treatment, with no observed differences in submergence times between crocodiles chronically maintained at $28^{\circ}$ and $34^{\circ} \mathrm{C}$ (fig. $1 \mathrm{~A}, 1 \mathrm{~B}$; single dives: $P=0.49, F_{1,10}=0.5$; consecutive diving: $P=0.83, F_{1,9}=0.0$; LME). Body mass had no effect on submergence times (single dives: $P=0.82, F_{1,7}=$ 0.1 ; consecutive diving: $P=0.38, F_{1,7}=0.9$; LME), and no significant covariate interactions were observed ( $P \geq 0.69$; LME).

Effect of Water Temperature on Postdive Plasma Lactate Concentrations and Comparisons among Activity States

Plasma lactate levels were independent of blood sampling times in all treatments $\left(P=0.81, F_{1,46}=0.06\right.$; LME; fig. 2$)$. Postdive
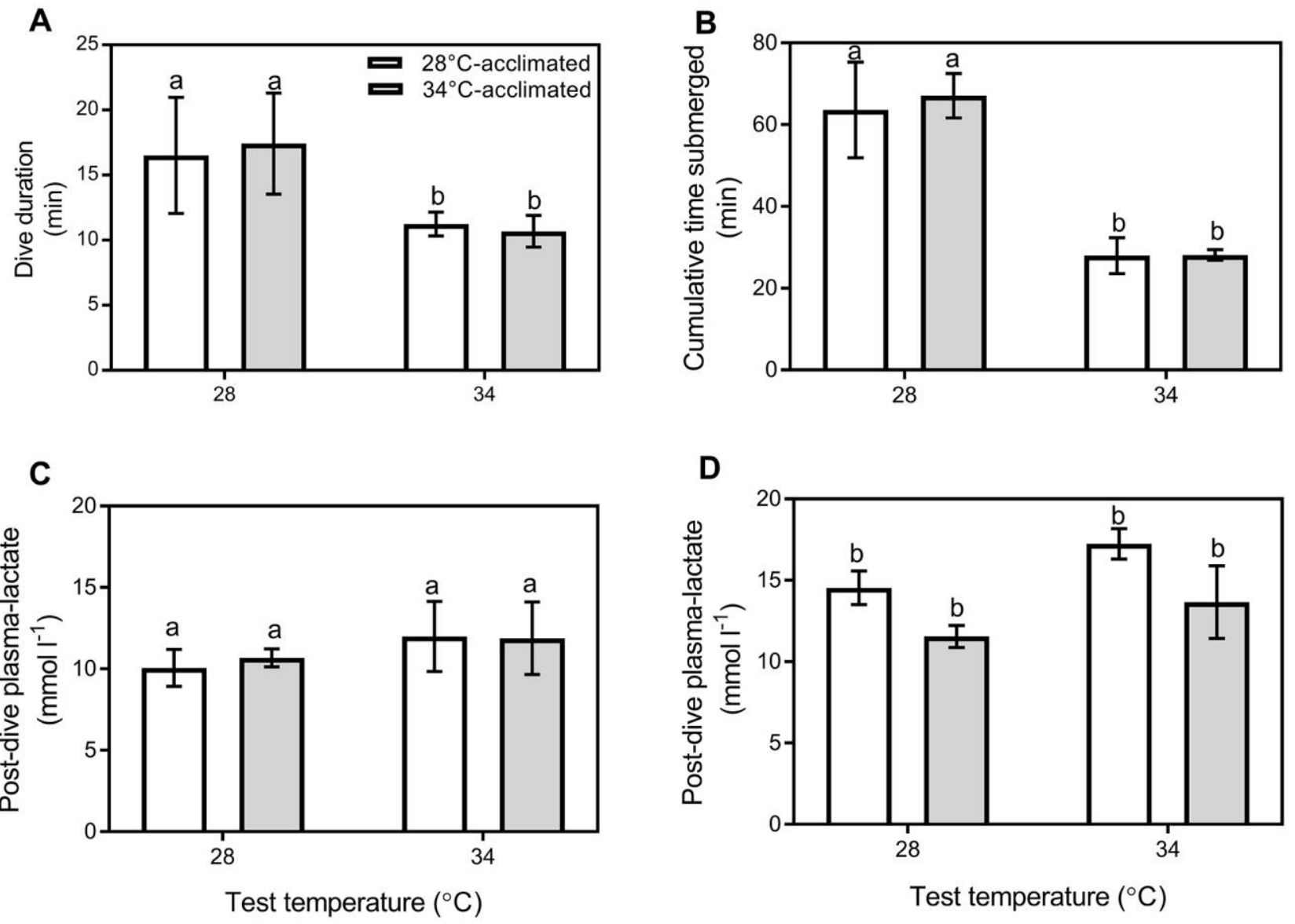

Figure 1. Thermal sensitivity of diving performance and postdive plasma lactate concentrations in juvenile estuarine crocodiles (Crocodylus porosus) exposed to two acclimation treatments $\left(28^{\circ}\right.$ or $\left.34^{\circ} \mathrm{C}\right)$ for $60 \mathrm{~d}$. Effects of test temperature on single simulated predator avoidance dive durations $(A)$, cumulative submergence time through a bout of four consecutive simulated predator avoidance dives $(B)$, postdive plasma lactate accumulation $\left(\mathrm{mmol} \mathrm{L}^{-1}\right)$ following a single predator avoidance dive $(C)$, and postdive plasma lactate accumulation following consecutive predator avoidance diving $(D)$. Dive durations were thermally sensitive but independent of thermal acclimation temperatures. Postdive plasma lactate levels were independent of thermal acclimation treatment and test temperature. Values are shown as means $\pm \operatorname{SE}(N=5-6)$, and different letters indicate statistical differences. 


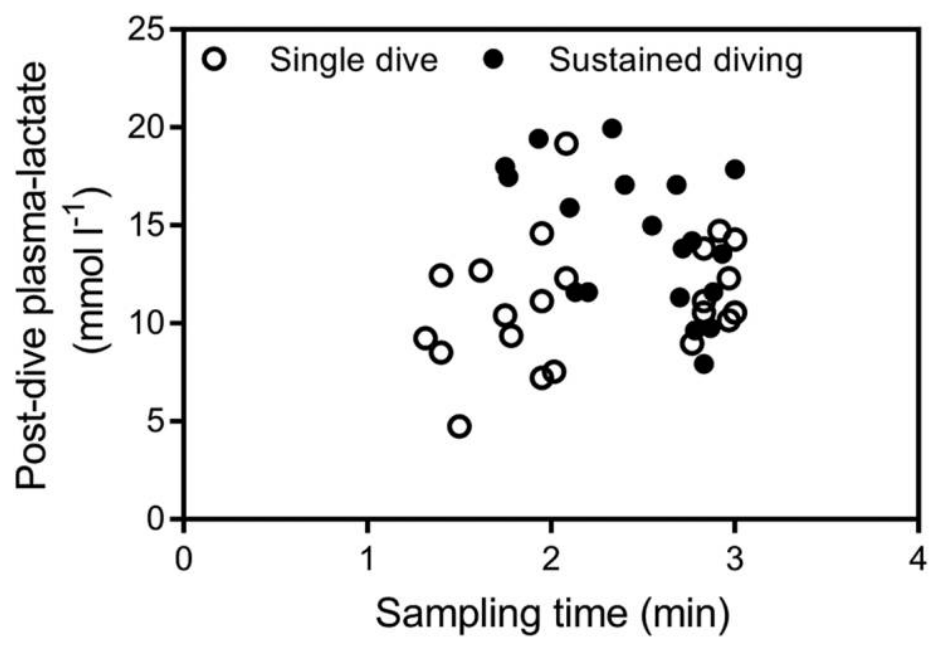

Figure 2. Relationship between blood sampling time ( $\mathrm{min}$ ) and plasma lactate accumulation $\left(\mathrm{mmol} \mathrm{L}^{-1}\right)$ following single (open circles) and consecutive (filled circles) simulated predator avoidance dive trials in juvenile estuarine crocodiles (Crocodylus porosus). Lactate concentrations were independent of blood sampling times. Test temperatures and acclimation treatments are pooled together because plasma lactate accumulation was independent of both factors. Values are shown as individual data points.

plasma lactate levels were independent of thermal acclimation treatment, test temperature, and body mass in both single and consecutive predator avoidance dives (table 1; fig. 1C, 1D). Similarly, resting and exercise-exhausted plasma lactate samples were independent of thermal acclimation treatment and body mass (table 1). The activity state of the animal (i.e., whether it was resting, exhausted, after single dive, or after consecutive predator avoidance diving) affected plasma lactate levels $(P<0.0001$, $F_{3,56}=123.0$; LME; fig. 3). Postdive plasma lactate concentrations were higher than resting levels $\left(28^{\circ} \mathrm{C}: 2.1 \pm 0.5 \mathrm{mmol} \mathrm{L}^{-1}\right.$;

Table 1: Full models for effects of acclimation treatment, test temperature, dive duration, and body mass on plasma lactate levels in juvenile estuarine crocodiles (Crocodylus porosus) at rest, following single and sustained predator avoidance dive trials and being run to exhaustion $(N=5-6)$

\begin{tabular}{|c|c|c|c|c|c|}
\hline Model and source of variation & Value & SE & $\mathrm{df}$ & $t$ & $P$ \\
\hline \multicolumn{6}{|l|}{ Resting: } \\
\hline Intercept & 1.51 & 1.09 & 9 & .214 & .84 \\
\hline Acclimation treatment & .09 & .58 & 3 & .88 & .41 \\
\hline Body mass & .00 & .00 & 6 & .85 & .43 \\
\hline Sampling time & 1.42 & 1.11 & 6 & 1.28 & .82 \\
\hline \multicolumn{6}{|l|}{ Single dive: } \\
\hline Intercept & 2.73 & 11.93 & 9 & .23 & .82 \\
\hline Test temperature & .16 & .25 & 8 & .65 & .54 \\
\hline Acclimation treatment & .07 & .27 & 9 & .24 & .82 \\
\hline Dive duration & .00 & .10 & 8 & .03 & .98 \\
\hline Body mass & .00 & .00 & 8 & .56 & .59 \\
\hline \multicolumn{6}{|l|}{ Sustained diving: } \\
\hline Intercept & -55.88 & 44.33 & 9 & -1.26 & .24 \\
\hline Test temperature & .76 & .33 & 1 & 2.31 & .26 \\
\hline Acclimation treatment & 1.62 & 1.5 & 9 & 1.07 & .31 \\
\hline Dive duration & -.10 & 1.28 & 1 & -.08 & .94 \\
\hline Body mass & .17 & .12 & 1 & 1.42 & .39 \\
\hline \multicolumn{6}{|l|}{ Exhausted: } \\
\hline Intercept & 17.60 & 3.38 & 9 & 5.21 & .99 \\
\hline Acclimation treatment & 1.34 & 2.16 & 3 & .62 & .62 \\
\hline Body mass & .01 & .00 & 6 & 1.31 & .83 \\
\hline Sampling time & 2.05 & 2.47 & 6 & .83 & .69 \\
\hline
\end{tabular}




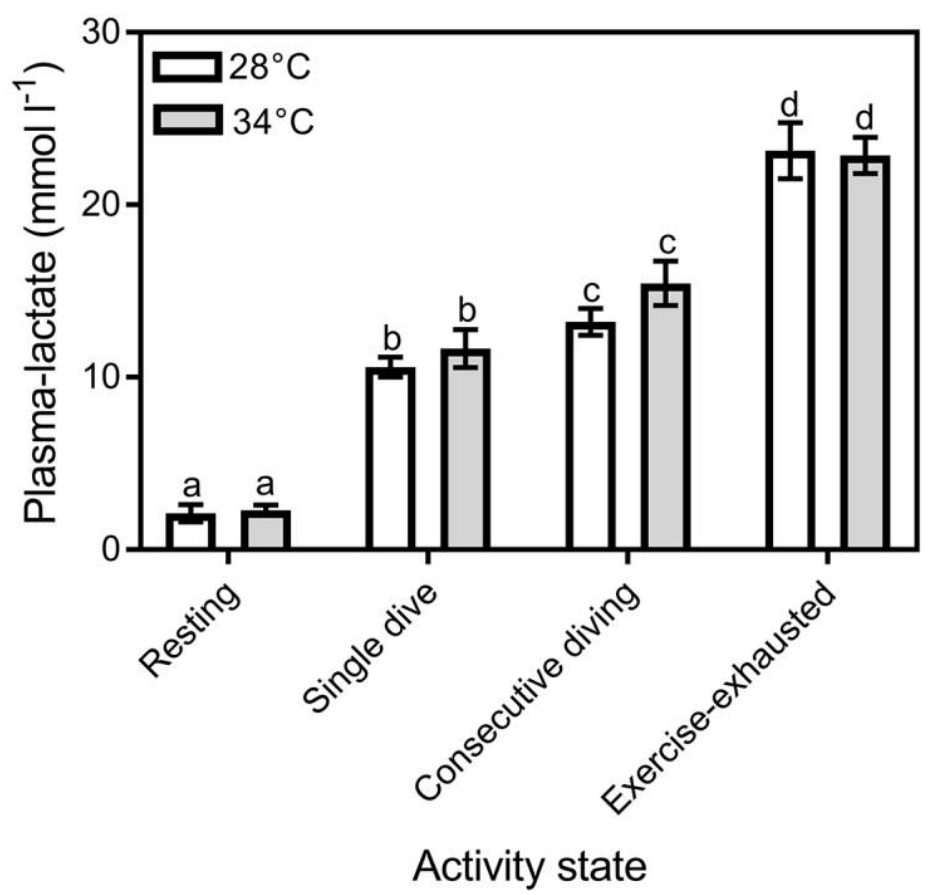

Figure 3. Plasma lactate accumulation ( $\mathrm{mmol} \mathrm{L}^{-1}$ ) at two test temperatures in juvenile estuarine crocodiles (Crocodylus porosus) following rest, a single simulated predator avoidance dive, a bout of four consecutive simulated predator avoidance dives, and being run to exhaustion $(N=10-12)$. Plasma lactate concentrations were dependent on activity state, with plasma lactate concentrations lowest in resting animals and highest following being run to exhaustion. Acclimation treatments are pooled together because plasma lactate was independent of acclimation treatment. Test temperature had no effect on plasma lactate concentration in any of the activity states. Columns indicate means \pm SE. Different letters indicate statistical differences.

$34^{\circ} \mathrm{C}: 2.3 \pm 0.3 \mathrm{mmol} \mathrm{L}{ }^{-1}$; mean $\pm \mathrm{SE}$ ), with approximately fivefold and sixfold increases for single and consecutive predator avoidance dives, respectively $(P<0.0001$; LME; fig. 3). Lactate accumulation was significantly greater following four consecutive predator avoidance dives compared with a single dive, with plasma lactate averaging $11.2 \pm 0.6 \mathrm{mmol} \mathrm{L}^{-1}$ (pooled mean $\pm \mathrm{SE}$ ) for single dives but reaching $14.0 \pm 0.7 \mathrm{mmol} \mathrm{L}^{-1}$ (pooled mean \pm $\mathrm{SE})$ for consecutive predator avoidance dives $(P<0.001$; LME; fig. 3). In crocodiles run to exhaustion, plasma lactate concentrations averaged $23.0 \pm 1.0 \mathrm{mmol} \mathrm{L}^{-1}$ (pooled mean $\pm \mathrm{SE}$ ) and were approximately twofold and 1.5-fold higher than after single and consecutive predator avoidance dives, respectively $(P<$ 0.001; LME; fig. 3). Dive duration had no effect on postdive plasma lactate levels in both single and consecutive predator avoidance dive trials (table 1).

\section{Total Body Oxygen Stores and Aerobic Dive Limits}

TBO stores at submergence were estimated to average $4.16 \mathrm{~mL}$ for a 408.1-g crocodile. ADLs for single simulated predator avoidance dives were estimated to be 6.7 and $2.0 \mathrm{~min}$ at $28^{\circ}$ and $34^{\circ} \mathrm{C}$, respectively (fig. $4 A$ ). When scaled up to four consecutive simulated predator avoidance dives (i.e., consecutive diving), aerobic thresholds for cumulative time spent underwater were estimated to be 26.8 and $8.1 \mathrm{~min}$ at $28^{\circ}$ and $34^{\circ} \mathrm{C}$, respectively (fig. $4 B$ ). All dives exceeded cADLS at $34^{\circ} \mathrm{C}$ in both single and consecutive dive trials (fig. 4), and approximately $90 \%$ of dives extended beyond cADLs at $28^{\circ} \mathrm{C}$ in both single and consecutive dive trials (fig. 4).

\section{Discussion}

Diving ectotherms may experience heightened predation risk under climate warming because of the inverse relationship between water temperature and submergence times (Rodgers et al. 2015). In this study we found that crocodiles surpassed ADLs during simulated predator avoidance dives (supporting $H_{1}$ ), but the extent of anaerobic support was thermally insensitive (rejecting $\mathrm{H}_{2}$ ) and did not differ between thermal acclimation treatments. Together, these findings suggest that crocodiles did not compensate for the thermal constraints on diving capacity by modulating anaerobic metabolism.

\section{Surpassing Aerobic Dive Limits}

Diving optimality models predict aerially respiring organisms to routinely dive within aerobic limits to maximize cumulative time underwater, but here we showed that simulated predator avoidance dives in Crocodylus porosus are an exception. Postdive plasma lactate levels surpassed resting levels at both test temperatures, and more than $90 \%$ of all dives exceeded cADLs, providing two lines of evidence to show that aerobic thresholds were surpassed. Although diving within aerobic limits is generally more efficient, 


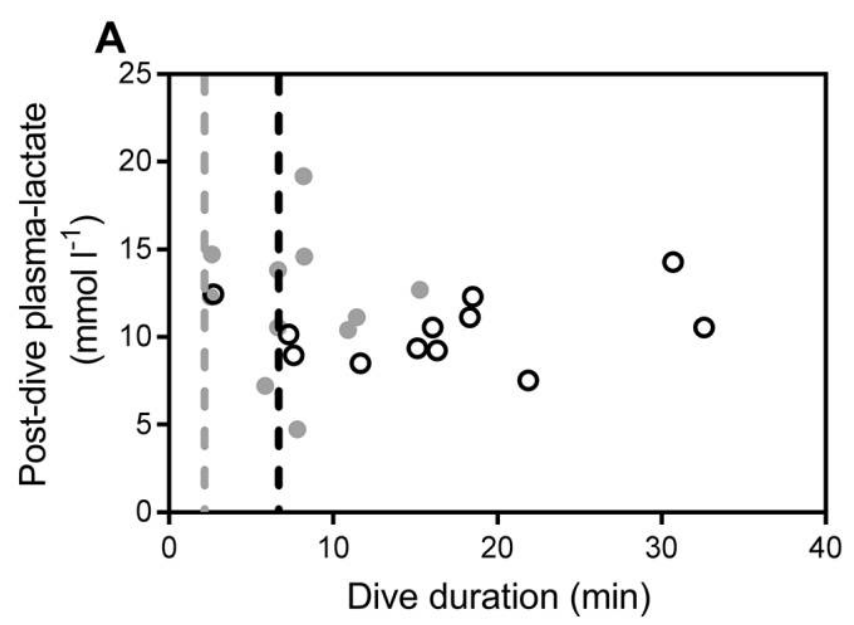

B

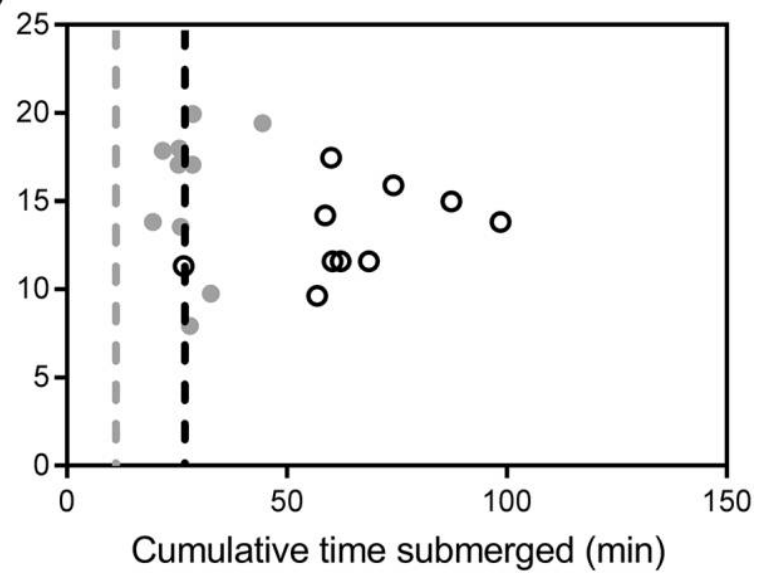

Figure 4. Effect of dive duration on postdive plasma lactate concentrations $\left(\mathrm{mmol} \mathrm{L}^{-1}\right)$ in juvenile estuarine crocodiles (Crocodylus porosus) performing a single simulated predator avoidance dive $(A)$ and a bout of four consecutive simulated predator avoidance dives $(B)$ at two test temperatures (white circles $=28^{\circ} \mathrm{C}$; gray circles $=34^{\circ} \mathrm{C} ; N=10-12$ ). Dashed lines represent calculated aerobic dive limits (cADLs) at both test temperatures (black line $=\mathrm{cADL}$ at $28^{\circ} \mathrm{C}$; gray line $=\mathrm{cADL}$ at $34^{\circ} \mathrm{C}$ ). Postdive plasma lactate levels were independent of dive duration in both conditions. All dives at $34^{\circ} \mathrm{C}$ exceeded aerobic thresholds, and $\sim 90 \%$ of dives at $28^{\circ} \mathrm{C}$ extended beyond cADLs. Data are shown as individual data points, and thermal acclimation treatments are pooled.

under predation pressure, surfacing early may be fatal. Utilizing anaerobic metabolism in life-threatening circumstances likely enhances survival probability and outweighs the costs of acidosis and obligate recovery periods (Bennett 1980). Indeed, anaerobiosis is an energy source regularly employed by ectotherms during predator attacks or territorial disputes where vigorous escape efforts are required and oxygen becomes limiting (Bennett et al. 1981; Domenici and Blake 1997). For instance, red-cheeked salamanders (Plethodon jordani) experiencing a direct predation threat from western terrestrial garter snakes (Thamnophis elegans) increased plasma lactate concentrations from resting levels by $880 \%$ and escaped predation in one-third of trials (Feder and Arnold 1982).

Although simulated predator avoidance dives were shown to be anaerobically supported, it is likely that dives serving other purposes, such as foraging, differ in their metabolic support. Maximizing time spent underwater can be achieved by performing a series of shorter dives within aerobic limits, so that extended postdive recovery periods can be avoided. In support of this idea, voluntary undisturbed dives in juvenile C. porosus are supported entirely by aerobic metabolism (Wright 1987). Applying the cADL calculations outlined here to dive recordings of wild C. porosus is an important next step and may provide an indication of how frequently ADLs are exceeded in natural settings. These calculations may prove particularly useful in assessing the diving behavior of large apex predators where obtaining postdive blood samples in under $3 \mathrm{~min}$ is logistically challenging. Our calculations provide a noninvasive alternative and may enable a range of research questions to be addressed, such as whether smaller crocodiles surpass cADLs more frequently than larger crocodiles, potentially owing to lower TBO stores and stronger predation pressure. However, our calculations are presently limited in scope because they pertain only to predator avoidance dives, and ob- taining estimates of oxygen uptake during foraging and resting dives would allow for the estimation of cADLs across a broader range of activities.

\section{Acute and Chronic Temperature Effects}

Crocodiles surfaced at similar plasma lactate concentrations regardless of water temperature, indicating that animals did not increase reliance on anaerobic metabolism at elevated temperatures. Instead, crocodiles surfaced approximately 5-7 min sooner at $34^{\circ} \mathrm{C}$ compared with $28^{\circ} \mathrm{C}$, regardless of thermal acclimation treatment. This finding may be indicative of crocodiles defending postdive oxygen debt and recovery durations, so that no additional time at the water surface was required following a dive at $34^{\circ} \mathrm{C}$ compared with $28^{\circ} \mathrm{C}$. Indeed, previous work has shown postdive oxygen debt to be thermally insensitive in $C$. porosus (Rodgers and Franklin 2017). Additionally, crocodiles appeared to spare some anaerobic reserves because postdive plasma lactate levels (single dive: $11.2 \pm 0.6 \mathrm{mmol} \mathrm{L}^{-1}$ [mean $\pm \mathrm{SE}$ ]; consecutive diving: $14.0 \pm 0.7 \mathrm{mmol} \mathrm{L}^{-1}[$ mean $\pm \mathrm{SE}]$ ) were substantially lower than levels reported for $C$. porosus run to exhaustion $\left(23.0 \pm 1.0 \mathrm{mmol} \mathrm{L}^{-1}[\right.$ mean $\left.\pm \mathrm{SE}]\right)$. Sparing anaerobic reserves during a predation threat may allow crocodiles to escape predators while replenishing oxygen stores at the surface by, for example, sprint swimming, but this behavior was not observed in our study. Alternatively, crocodiles may have surfaced once plasma lactate levels reached a critical threshold $\left(\sim 11.2 \mathrm{mmol} \mathrm{L}^{-1}\right)$, because the blood $\mathrm{pH}$ decrease associated with this lactate threshold stimulated central chemoreceptors and evoked breathing behavior; however, the mechanisms underlying this behavior remain unexplored.

Although postdive plasma lactate levels were higher following consecutive diving (i.e., four consecutive dives) compared with a single dive, levels were less than four times higher. This cannot be 
attributed to changes in diving behavior, because average dive durations in the consecutive trials were comparable to submergence times recorded in the single-dive trials. Unlike most diving organisms, the bulk of TBO in C. porosus is stored in the lungs (67\%; Wright 1985); hence, a rapid breath over a short surfacing period (3.6 s) may have been sufficient for partial replenishment of TBO stores. In support of this idea, postdive oxygen uptake rates in tufted ducks (Aythya fuligula) are extremely rapid during the first $3 \mathrm{~s}$ of surfacing (Parkes et al. 2002). Examining rates of oxygen uptake throughout consecutive bouts of diving would provide valuable insight. Postdive plasma lactate concentrations did not correlate with dive duration. This lack of correlation may result from differences in TBO stores among individuals (e.g., body size differences or individuals diving on exhalation vs. inhalation) or variation in DMR, as some individuals may have displayed a stronger fright response than others.

The thermal insensitivity of anaerobiosis during simulated predator avoidance dives contrasts to observations of juvenile $C$. porosus swimming at elevated temperatures (Campbell et al. 2013). Swimming performance (i.e., distance swum) of juvenile C. porosus was maintained at $28^{\circ}-33^{\circ} \mathrm{C}$, but maintaining performance at $33^{\circ} \mathrm{C}$ came at the cost of increased oxygen debt ( $\sim 10$-fold increase) and extended recovery durations (approximately threefold increase; Campbell et al. 2013). This discrepancy between metabolic partitioning may be due to behavioral strategies that optimize different outputs (i.e., total time underwater versus total distance swum), or the end point of dive trials may be more volitional compared with swimming trials in recirculating flumes.

Chronic exposure to the elevated temperature did not elicit changes in diving performance, demonstrating a lack of phenotypic plasticity. Limited thermal phenotypic plasticity has previously been reported in C. porosus (Rodgers et al. 2015; Rodgers and Franklin 2017) and appears to be a common characteristic in diving ectotherms. For example, diving performance in the Mary River turtle (Elusor macrurus) only partially acclimated to elevated water temperatures (Clark et al. 2008). A lack of physiological compensation deems this group particularly susceptible to climate warming, and elevated temperatures may see these species forced to spend more time at the water surface where conspicuousness to predators is greatest.

\section{Ecological Relevance and Implications}

A multitude of factors likely influence diving behavior and physiology of air-breathing ectotherms. Many diving species may fall prey to both aerial and aquatic predators, and responses can change depending on predator type and abundance (Pratt and Franklin 2009). Adding further complexity, crocodylians also dive to pursue aquatic prey (e.g., crustaceans and fish), and trade-offs between energy gains and predation risk likely influence diving decisions (Heithaus and Dill 2002; Frid et al. 2007b). For example, free-ranging harbor seals (Phoca vitulina richardsi) underexploited prey-rich patches when predation risk from Pacific sleeper sharks (Somniosus pacificus) was high (Frid et al. 2007a).

The findings presented here advance our understanding of the interactions between water temperature and metabolic par- titioning during simulated predator avoidance dives in an airbreathing ectotherm. Reliance on anaerobic metabolism appears to be important, regardless of water temperature. The thermal sensitivity of diving performance and lack of anaerobic compensation suggest that juvenile C. porosus may be more frequently exposed to predators if habitat water temperatures continue to rise under climate change. However, antipredator behavior is not limited to physiological changes, and exploring a range of antipredator behavior in response to elevated temperatures is recommended for future endeavors. For example, aquatic air breathers can surface synchronously to lower predation probability, preferentially surface in areas with few aerial predators, and reduce underwater activity levels when near predators (Kramer and Graham 1976; Kramer et al. 1983; Clark 2008). Diving ectotherms may also offset the thermal constraints on diving capacity by seeking out cooler water in thermally stratified water bodies or by performing poleward migrations. In conclusion, our findings suggest that increasing reliance on anaerobic metabolism at elevated temperatures is not a compensatory strategy employed by C. porosus, and unless behavioral compensation is employed, $C$. porosus and other air-breathing diving ectotherms may be forced to spend more time at the water surface where predation risk is highest.

\section{Acknowledgments}

We thank R. Cramp for advice and insightful discussions. Many thanks are extended to all volunteers who assisted with crocodile husbandry: D. Gomez Isaza, M. Elmer, C. Dudal, H. Goodrich, N. Wu, C. Ahlgren, D. Stark, and N. Clark. This work was supported in part by an Australian Research Council Linkage Grant awarded to C.E.F., and funding was provided by the University of Queensland.

\section{Literature Cited}

Axelsson M. and C.E. Franklin. 1997. From anatomy to angioscopy: 164 years of crocodilian cardiovascular research, recent advances, and speculations. Comp Biochem Physiol A 118:5162.

Bennett A.F. 1980. The metabolic foundations of vertebrate behavior. BioScience 30:452-456.

Bennett A.F., T.T. Gleeson, and G.C. Gorman. 1981. Anaerobic metabolism in a lizard (Anolis bonairensis) under natural conditions. Physiol Zool 54:237-241.

Boyd I.L. 1997. The behavioral and physiological ecology of diving. Trends Ecol Evol 12:213-217.

Bradshaw C.J., C.R. McMahon, and G.C. Hays. 2007. Behavioral inference of diving metabolic rate in free-ranging leatherback turtles. Physiol Biochem Zool 80:209-219.

Butler P.J. 2006. Aerobic dive limit: what is it and is it always used appropriately? Comp Biochem Physiol A 145:1-6.

Campbell H.A., R.G. Dwyer, M. Gordos, and C.E. Franklin. 2010. Diving through the thermal window: implications for a warming world. Proc Biol Sci 277:3837-3844. 
Campbell H.A., O. Sissa, R.G. Dwyer, and C.E. Franklin. 2013. Hatchling crocodiles maintain a plateau of thermal independence for activity, but at what cost? LHerpetol 47:11-14.

Carr A., L. Ogren, and C.J. McVea. 1980. Apparent hibernation by the Atlantic loggerhead turtle off Cape Canaveral, Florida. Biol Conserv 19:7-14.

Clark N.J. 2008. The diving physiological ecology of Australian freshwater turtle hatchlings. $\mathrm{PhD}$ diss. University of Queensland, Brisbane.

Clark N.J., M.A. Gordos, and C.E. Franklin. 2008. Thermal plasticity of diving behavior, aquatic respiration, and locomotor performance in the Mary River turtle Elusor macrurus. Physiol Biochem Zool 81:301-309.

Costa D.P., C.E. Kuhn, M.J. Weise, S.A. Shaffer, and J.P.Y. Arnold. 2004. When does physiology limit the foraging behavior of freely diving mammals? Int Congress Ser 1275:359-366.

Domenici P. and R. Blake. 1997. The kinematics and performance of fish fast-start swimming. LExp Biol 200:1165-1178.

Feder M.E. and S.J. Arnold. 1982. Anaerobic metabolism and behavior during predatory encounters between snakes (Thamnophis elegans) and salamanders (Plethodon jordani). Oecologia 53:93-97.

Finger J.W., P.C. Thomson, A.L. Adams, S. Benedict, C. Moran, and S.R. Isberg. 2015a. Reference levels for corticosterone and immune function in farmed saltwater crocodiles (Crocodylus porosus) hatchlings using current Code of Practice guidelines. Gen Comp Endocrinol 212:63-72.

Finger J.W., R.J. Williams, M.T. Hamilton, R.M. Elsey, V.A. Oppenheimer, S.D. Holladay, and R.M. Gogal. 2015b. Influence of collection time on hematologic and immune markers in the American alligator (Alligator mississippiensis). IImmunoassav Immunochem 36:496-509.

Franklin C.E. and M. Axelsson. 2000. An actively controlled heart valve. Nature 406:847-848.

Franklin C.E., M.D. Bernie, S.K.J. Peucker, H. Stephenson, R. Mayer, M.J. Whittier, and G.C. Grigg. 2003. Comparison of stress induced by manual restraint and immobilisation in the estuarine crocodile, Crocodylus porosus. LExp Zool 298:8692.

Franklin C.E., M.A. Read, P.G. Kraft, N. Liebsch, S.R. Irwin, and H.A. Campbell. 2009. Remote monitoring of crocodilians: implantation, attachment and release methods for transmitters and data-loggers. Mar Freshw Res 60:284-292.

Frid A., L.M. Dill, R.E. Thorne, and G.M. Blundell. 2007a. Inferring prey perception of relative danger in large-scale marine systems. Evol Ecol Res 9:635-649.

Frid A., M.R. Heithaus, and L.M. Dill. 2007b. Dangerous dive cycles and the proverbial ostrich. Oikos 116:893-902.

Gordos M.A., C.J. Limpus, and C.E. Franklin. 2003. Seasonal changes in the diving performance of the bimodally respiring freshwater turtle Rheodytes leukops in a natural setting. Can I Zool 81:617-625.

Grigg G.C., W.D. Farwell, J.L. Kinney, P. Harlow, L.E. Taplin, K. Johansen, and K. Johansen. 1985. Diving and amphibious behavior in a free-living Crocodylus porosus. Aust Zool 21:599604.
Grigg G.C. and D. Kirshner. 2015. Biology and evolution of crocodylians. CSIRO, Clayton South.

Hayward A., M. Pajuelo, C.G. Haase, D.M. Anderson, and J.F. Gillooly. 2016. Common metabolic constraints on dive duration in endothermic and ectothermic vertebrates. PeerJ 4:e2569.

Heithaus M.R. and L.M. Dill. 2002. Food availability and predation risk influence bottlenose dolphin habitat use. Ecology 83:480-491.

Heithaus M.R., L.M. Dill, G.J. Marshall, and B.M. Buhleier. 2002. Habitat use and foraging behavior of tiger sharks ( $\mathrm{Ga}$ leocerdo cuvier) in a seagrass ecosystem. Mar Biol 140:237-248.

Heithaus M.R. and A. Frid. 2003. Optimal diving under the risk of predation. LTheor Biol 223:79-92.

Hochscheid S., F. Bentivegna, N. Bradai, and G.C. Hays. 2007. Overwintering behavior in sea turtles: dormancy is optional. Mar Ecol Prog Ser 340:287-298.

Hochscheid S., F. Bentivegna, and G.C. Hays. 2005. First records of dive durations for a hibernating sea turtle. Biol Lett 1:82-86.

Houston A.I. and J.M. McNamara. 1992. The optimal allocation of time during the dive cycle. Behav Ecol 3:233-262.

Huggins S.E. 1961. Blood volume parameters of a poikilothermal animal in hypo- and hyperthermia. Proc Soc Exp Biol Med 108:231-234.

Kramer D.L. 1988. Behavioral ecology of air breathing by aquatic mammals. Can I Zool 66:89-94.

Kramer D.L. and J.B. Graham. 1976. Synchronous air breathing, a social component of respiration in fishes. Copeia 1976:689697.

Kramer D.L., D. Manley, and R. Bourgeois. 1983. The effect of respiratory mode and oxygen concentration on the risk of aerial predation in fishes. Can I Zool 61:653-665.

Kooyman G.L. 1989. Diverse divers: physiology and behavior. Springer, Berlin.

Kooyman G.L., M.A. Castellini, R.W. Davis, and R.A. Maue. 1983. Aerobic diving limits of immature Weddell seals. LComp Physiol 151:171-174.

Kooyman G.L., E.A. Wahrenbrock, M.A. Castellini, R.W. Davis, and E.E. Sinnett. 1980. Aerobic and anaerobic metabolism during voluntary diving in Weddell seals: evidence of preferred pathways from blood chemistry and behavior. LComp Physiol 138:335-346.

Parkes R., L.G. Halsey, A.J. Woakes, R.L. Holder, and P.J. Butler. 2002. Oxygen uptake during post dive recovery in a diving bird Aythya fuligula: implications for optimal foraging models. LExp Biol 205:3945-3954.

Pratt K.L. and C.E. Franklin. 2009. Predator or prey? the dive response to aerial and aquatic predators of Arafura filesnakes. Aust I Zool 57:423-428.

. 2010. Temperature independence of aquatic oxygen uptake in an air-breathing ectotherm and the implications for dive duration. Comp Biochem Physiol A 156:42-45.

Priest T.E. and C.E. Franklin. 2002. Effect of water temperature and oxygen levels on the diving behavior of two freshwater turtles: Rheodytes leukops and Emydura macquarii. L Herpetol 36:555-561. 
R Development Core Team. 2012. R: a language and environment for statistical computing. R Foundation for Statistical Computing, Vienna. http://www.R-project.org/.

Rodgers E.M. and C.E. Franklin 2017. Physiological mechanisms constraining ectotherm fright-dive performance at elevated temperatures. IExp Biol 220:3556-3564.

Rodgers E.M., J.J. Schwartz, and C.E. Franklin 2015. Diving in a warming world: the thermal sensitivity and plasticity of diving performance in juvenile estuarine crocodiles (Crocodylus porosus). Conserv Physiol 3:cov054.

Samajova P. and L. Gvozdik. 2009. The influence of temperature on diving behavior in the alpine newt, Triturus alpestris. ITherm Biol 34:401-405.

Storey E.M., S.M. Kayes, I. De Vries, and C.E. Franklin. 2008. Effect of water depth, velocity and temperature on the surfacing frequency of the bimodally respiring turtle Elseya albagula. Funct Ecol 22:840-846.

Strong W.R. 1996. Shape discrimination and visual predatory tactics in white sharks. Pp. 229-240 in A.P. Klimley and A.D.
Ainley, eds. Great white sharks: the biology of Carcharodon carcharias. Academic Press, New York.

Udyawer V., C.A. Simpfendorfer, M.R. Heupel, and T.D. Clark. 2016. Coming up for air: thermal dependence of dive behaviors and metabolism of sea snakes. LExp Biol 219:34473454.

Wright J.C. 1985. Diving and exercise physiology in the estuarine crocodile, Crocodylus porosus. $\mathrm{PhD}$ diss. University of Sydney.

. 1987. Energy metabolism during unrestrained submergence in the saltwater crocodile Crocodylus porosus. Physiol Zool 60:515-523.

Wright J.C., G.C. Grigg, and C.E. Franklin. 1992. Redistribution of air within the lungs may potentiate "fright" bradycardia in submerged crocodiles (Crocodylus porosus). Comp Biochem Physiol A 102:33-36.

Wright J.C. and D.S. Kirshner 1987. Allometry of lung volume during voluntary submergence in the saltwater crocodile Crocodylus porosus. J Exp Biol 130:433-436. 